\title{
PROCESSO DE \\ AMBIENTALIZAÇÃO E PROMOÇÃO DA SUSTENTABILIDADE NA UDESC: ANÁLISE DOS DOCUMENTOS INSTITUCIONAIS E CURRICULARES
}

\author{
Ana Waley Mendonça ${ }^{1}$ \\ Mario Jorge Cardoso de Freitas ${ }^{2}$ \\ Atalita Soethe Ghizoni ${ }^{3}$ \\ Amauri Bogo 4 \\ Isabel Cristina da Cunha ${ }^{5}$
}

Resumo: $O$ artigo trata de análise preliminar do processo de ambientalização e sustentabilidade, identificando indícios de ambientalização nos documentos institucionais e curriculares, nos níveis de gestão, ensino, pesquisa e extensão do campus I da Universidade do Estado de Santa Catarina. A busca pela ambientalização e sustentabilidade foi norteada pelo indicador incidência/ocorrência; pelos níveis e onze dimensões. A metodologia caracterizou-se pelo enfoque quanti-qualitativo com base na pesquisa-ação participante utilizando o programa MAXQDA®. Os resultados apontam que em todos os níveis se evidencia o comprometimento com a temática, embora ainda numa perspectiva fragmentada e isolada nos referidos documentos.

Palavras-chave: Políticas Institucionais; Ambientalização Curricular; Educação Ambiental; Sustentabilidade.

\footnotetext{
${ }^{1}$ Professora da Universidade do Sul de Santa Catarina - Unisul e do Centro de Educação a Distância CEAD/UDESC. E-mail: ana.waley@gmail.com

2 Professor do Centro de Ciências Humanas e da Educação - FAED/UDESC. E-mail: pmariofreitas@gmail.com

${ }^{3}$ Graduada em Ciências Econômicas - ESAG/UDESC. E-mail: atalitaghizoni2008@hotmail.com

4 Centro de Educação a Distância - CEAD - Universidade do Estado de Santa Catarina- UDESC. E-mail: amauri.bogo@udesc.br

${ }^{5}$ Universidade do Estado de Santa Catarina- UDESC. E-mail: dacunhaic@gmail.com
} 


\section{Introdução}

Este artigo é um recorte de um dos subprojetos que integram o Projeto "Ambientalização e Sustentabilidade na Educação Superior: Subsídios às Políticas Institucionais em Santa Catarina", realizado com base na parceria de oito Instituições de Educação Superior (IES), localizadas em cinco mesorregiões de Santa Catarina: Universidade do Extremo Sul Catarinense (Unesc), Universidade do Sul de Santa Catarina (Unisul), Universidade do Alto Vale do Itajaí (Unidavi), Universidade do Vale do Itajaí (Univali), Centro Universitário de Brusque (Unifebe), Universidade do Planalto Catarinense (Uniplac), Universidade do Oeste de Santa Catarina (Unoesc) e Universidade do Estado de Santa Catarina (Udesc) com fomento da FAPESC, Edital № 01/2014.

Numa primeira fase do projeto foram efetivadas entrevistas com os órgãos de governo das universidades pedindo-lhes que respondessem a um conjunto de questões que incidiam sobre o grau de atingimento, pela universidade, de um conjunto de indicadores de ambientalização/sustentabilidade, elaborados no âmbito do projeto RISU ${ }^{6}$. A análise dos resultados permitiu realizar um diagnóstico do que foi ou não foi feito, neste âmbito, pelas universidades e quais eram seus compromissos para o futuro (DA CUNHA et al., 2015). Após esse diagnóstico, o projeto centrou-se na identificação de indícios de ambientalização/sustentabilidade nos documentos institucionais de cada instituição. Este artigo se constitui, como já se referiu, em um recorte desse segundo momento do projeto e, mais especificamente, na identificação de indícios de ambientalização, no âmbito da gestão, ensino, pesquisa e extensão a partir da análise dos documentos institucionais - Plano de Desenvolvimento Institucional (PDI), Projeto Pedagógico Institucional (PPI) - e curriculares Projetos Pedagógicos dos Cursos (PPC) dos cursos do campus I.

Como objetivo verificou-se o estágio do processo de ambientalização e sustentabilidade, identificando indícios de ambientalização a partir da análise dos documentos institucionais e curriculares, nos níveis de gestão, do ensino, da pesquisa, da extensão do campus I da Udesc.

\section{Considerações sobre a Ambientalização e Sustentabilidade no ensino superior}

Desde a revolução industrial que as relações entre o homem e o ambiente foram acumulando contradições. Durante o século XX essas contradições tomaram a forma de graves acidentes ambientais que foram semeando preocupações em instâncias nacionais e internacionais. Em grande parte por causa de tais acidentes e de seu real significado, desde o final dos anos sessenta do século passado que várias iniciativas, em diferentes domínios, veem alertando para a necessidade de promover novos equilíbrios ambientais. Dentre

\footnotetext{
${ }^{6}$ Rede de Indicadores de Universidades Sustentáveis (RISU), constituída, em junho de 2012 junto à Universidade do Vale do Itajaí (Univali), no âmbito da Aliança de Redes Iberamericanas de Universidades para a Sustentabilidade e Ambiente.
}

Revbea, São Paulo, V,13, № 1: 283-298, 2018. 
tais iniciativas podemos realçar a emergência e consolidação da Educação Ambiental, do Direito Ambiental e de várias disciplinas que integram as chamadas Ciência Ambientais.

Apesar de muitos alertas e vários esforços de moderação, em grande parte decorrentes das iniciativas globais que acabamos de referir, a degradação ambiental continuou provocando: destruição ou séria alteração de ecossistemas e habitats naturais e seminaturais, com inevitáveis consequências em termos de biodiversidade; esgotamento ou séria diminuição da quantidade e qualidade dos recursos naturais de que depende a vida; em particular, degradação da qualidade da água, do ar e dos solos, com sérias consequências da qualidade de vida humana e de outros seres, etc. Foi devido a essa realidade que cerca de duas décadas mais tarde emergem os conceitos de desenvolvimento sustentável e sociedades sustentáveis, trazendo a ideia de sustentabilidade para as discussões científicas e políticas, em que interveem vários atores, segmentos e setores da sociedade.

Segundo Leonardo Boff (2012 apud CARNIATTO; STEDING, 2015, p. 301) "a sustentabilidade deve acolher a totalidade do Sistema Terra, o Sistema Vida e o Sistema Vida Humana”. Várias mobilizações de caráter social e ambiental, instituídas e/ou conduzidas por organizações preocupadas com o presente e futuro da humanidade, têm destacado que a relação do homem com a natureza precisa de alternativas que visem a sustentabilidade e que tal se revela essencial para a sobrevivência das gerações futuras, sem colocar em causa a qualidade de vida das gerações atuais.

Neste contexto, entram em cena as instituições de ensino superior, como instrumentos de excelência para a construção e disseminação de saberes que fornecem uma base mais segura para a definição e implementação de políticas e estratégias de ambientalização e sustentabilidade. Mas, apesar de variadas iniciativas já empreendidas (DA CUNHA et al., 2015), o panorama está longe do desejável e as universidades precisam adotar novos modelos e passar por mudanças que perpassam as esferas administrativas, técnicas e acadêmicas de forma a comprometer toda a comunidade, no que diz respeito a fomentar tipos de ensino, pesquisa e extensão que promovam a ambientalização e, assim, contribuam para a construção de universidades e sociedades mais sustentáveis. É o que afirmam vários autores como, por exemplo, Sorrentino e Biasoli (apud RUSCHEINSKY et al., 2014, p. 45):

A formulação e a implantação de políticas públicas comprometidas com a transformação de nossas sociedades em direção à sustentabilidade socioambiental exigem a ambientalização de todas as instituições e movimentos instituintes, e o papel a ser jogado pelas IES nesse panorama é absolutamente relevante. Pode-se iniciar tal missão pela revisão de seus currículos, gestão, construções e relacionamentos comunitários. Deve-se começar pela ambientalização das próprias IES, criando políticas indutoras nessa direção.[...]. 
Nesta direção cabe à universidade inserir nos seus currículos a ambientalização, instituir em seu sistema pedagógico uma série de mudanças que contemplem inovações conceituais, metodológicas, atitudinais e organizacionais, com enfoque interdisciplinar. (BOLEA, 2004 apud GUERRA; FIGUEIREDO, 2014).

Kitzmann (2007, p. 553-554 apud GUERRA; FIGUEIREDO, 2014, p. 115) reforça que é necessário que 0 :

processo de ambientalização esteja norteado em critérios e princípios definidos de forma clara e abrangente, assim como ser realizado de forma sistêmica, considerando tanto a reforma curricular quanto institucional de modo a garantir a sua adequada implementação.

A inclusão da ambientalização no ensino superior é necessária, já que este é o responsável pela formação nos níveis de graduação e pós-graduação de profissionais de vários domínios do saber e esferas de ação. Esta apropriação de saberes em relação ao ambiente poderá contribuir de forma significativa na construção de uma sociedade com menos problemas ambientais e, como tal, mais sustentável. Copello (2006, p. 93-94 apud ROCHA; PEREIRA; BARBOSA, 2016) argumenta em favor de uma ideia de que a

[...] ambientalização compromete a escola na sua organização e funcionamento, bem como cada um de seus membros individualmente. Afeta o currículo explícito e também o currículo oculto. Fundamenta-se no pensamento divergente, na criatividade, na procura de novas formas de trabalho coletivo que superem rotinas acríticas, que capacitem para a ação comprometida com uma comunidade para a qual a escola se abre, da qual se sente parte integrante e com a qual se compromete. [...].

Guerra e Figueiredo (2014, p. 116) afirmam que a "ambientalização deve promover um questionamento constante e aberto sobre os conhecimentos e suas produções tendo em vista o favorecimento da formação integral dos estudantes [...]." Neste sentido a contribuição das universidades para a promoção da sustentabilidade, tem se tornado cada vez mais necessária e abrangente. Além do seu papel educacional, desde a Declaração de Kyoto, 1993, é colocado em pauta a necessidade de encorajar as universidades a rever suas ações institucionais e desenvolver de fato melhores práticas para 0 desenvolvimento da sustentabilidade. (LEITE apud RUSCHEINSKY et al., 2014).

Nas universidades o conhecimento é desenvolvido por meio da articulação entre ensino, pesquisa e extensão, possibilitando aos acadêmicos novos saberes, que vão contribuir para processos de transformação individual e social e assim, cabe as instituições de ensino superior contemplar efetivamente Revbea, São Paulo, V,13, № 1: 283-298, 2018. 
exemplos de sustentabilidade nas dimensões social, cultural, econômico e ambiental.

\section{Metodologia}

A abordagem metodológica caracterizou-se pelo enfoque quantiqualitativo e o uso de técnicas de análise documental (PIMENTEL, 2001; LÜDKE; ANDRÉ, 2003; RICHARDSON, 1999) e análise de conteúdo (BARDINI, 2008; FRANCO, 2008). Os documentos institucionais analisados pelo grupo de pesquisadores da Udesc foram: PDI e PPI e curriculares (PPC) dos seguintes centros do campus I: Centro de Educação a Distância-CEAD, Centro de Artes CEART, Centro de Ciências da Administração e Socioeconômicas- ESAG e Centro de Ciências Humanas e da Educação- FAED.

A análise apresentada neste artigo faz parte de um projeto de pesquisa maior, em andamento, entre 8 IES do Estado de Santa Catarina. Neste trabalho a busca pela ambientalização e sustentabilidade nos referidos documentos foi norteada pelo indicador denominado incidência/ocorrência (que é medido por palavras chave e posterior análise qualitativa de comprovação);pelos níveis: gestão, ensino, pesquisa e extensão e pelas onze dimensões (de $A$ a $K$ ) baseadas: na Rede de Ambientalização Curricular do Ensino Superior (ACES) ${ }^{7}$; na adaptação dos 113 indicadores de sustentabilidade do projeto Definición de indicadores de evaluación de la sustentabilidade en Universidades Latino americanas-RISU (BENAYAS, 2014) e nos 10 indicadores desenvolvidos pelo Grupo de Pesquisa Educação Estudos Ambientais e Sociedade (GUERRA et al., 2015). As onze dimensões são as seguintes:

A. Política de ambientalização/sustentabilidade/meio ambiente/responsabilidade socioambiental;

B. Gerenciamento e/ou monitoramento de bens e serviços naturais (recursos), riscos e impactos ambientais;

C. Sensibilização, participação democrática e comunicação (“Educação Ambiental");

D. Compromisso para a transformação das relações ser humanosociedade-natureza;

E. Complexidade: diálogo em torno da ecologia de saberes, trabalho em redes;

\footnotetext{
${ }^{7}$ Os quais são: 1. Compromisso para a transformação das relações sociedade-natureza; 2. Complexidade; 3 . Ordem disciplinar (flexibilidade e permeabilidade); 4. Contextualização local global, local e global; 5 . Considerar o sujeito na construção do conhecimento; 6 . Consideração aos aspectos cognitivos e afetivos das pessoas; 7 . Coerência e reconstrução entre teoria e prática; 8. Orientação de cenários alternativos; 9. Adequação metodológica; 10. Espaços de reflexão e participação democrática (JUNYENT; GELI; ARBAT, 2003, p. 22. Tradução equipe projeto FAPESC).
} 
F. Contextualização local, global, local-global, global-local;

G. Consideração dos sujeitos na construção dos saberes e fazeres;

H. Consideração das relações com a comunidade e o entorno;

I. Coerência e reconstrução entre teoria e prática;

J. Construção de espaços permanentes de reflexão, formação e atualização;

K. Adoção de valores como solidariedade, cooperação e responsabilidade.

Para a análise dos documentos foi utilizado o MAXQDA® que é um programa que permite organizar e sistematizar os dados coletados facilitando a criação de relatórios. O MAXQDA apenas identifica a presença das palavraschave. No processo de codificação com este programa foram realizadas buscas lexicais nos documentos institucionais por meio de palavras-chave identificando trechos que apontavam a relação com cada uma das onze dimensões. Os trechos foram analisados e inseridos nas dimensões correspondentes. $\mathrm{Na}$ análise documental buscou-se identificar o indicador: indício e ocorrência das 11 dimensões nos níveis da gestão, pesquisa, extensão e ensino. Como critério metodológico, em comum acordo com o grupo de pesquisadores das oito instituições, foram selecionados para análise apenas os Projetos Pedagógicos dos Cursos- PPC que contemplavam, no mínimo, três das 11 dimensões. Do total de 16PPCs (o curso de Design se divide em Industrial e Gráfico contemplando um mesmo PPC) analisados, 10 deles contemplaram pelo menos três dimensões. Os documentos institucionais foram armazenados no programa MAXQDA $\AA$, sistematizados e gerados em formato de planilhas eletrônicas do Microsoft Exce® para consulta e análise.

\section{Apresentação e análise dos resultados}

O PDI e o PPI da Udesc integram um documento extenso com quase 200 páginas: 136 dedicadas aos PDI e as restantes ao PPI. O PDI "define a missão da Instituição e as estratégias para alcançar suas metas e objetivos" (UDESC, 2016, p. 8). Trata-se de "documento base, cujos dados numéricos são atualizados anualmente, para a elaboração do planejamento anual da Udesc e para o acompanhamento do planejamento estratégico, denominado Plano 20 , que tem um alcance temporal de 20 anos" (id. ibid.). No referido documento, após a introdução, traça-se o perfil institucional da universidade, o histórico e apresenta-se a missão, visão de futuro, princípios e finalidade. A ideia de sustentabilidade aparece logo aí, na explanação da missão da universidade: "...contribuir para uma sociedade mais justa e democrática em prol da qualidade de vida e do desenvolvimento sustentável do Estado de Santa Catarina e do País" (UDESC, 2016, p. 22). Na explicitação da finalidade surgem, de novo, referências que se coadunam com a ambientalização e a sustentabilidade: 
contribuir para a "....construção de uma sociedade democrática, plural e ética", para "promover a inclusão social e étnica, respeitando a diversidade cultural" e "para o desenvolvimento local, regional e nacional, visando à melhoria da qualidade de vida da sociedade, com a busca da erradicação das desigualdades sociais e a utilização de tecnologias ecologicamente orientadas" (UDESC, 2016, p. 22-23). Nas páginas seguintes aparecem Indicadores quantitativos relativos a cursos, disciplinas e alunos de graduação e pós-graduação, projetos institucionais desenvolvidos, bolsas, atividades de pesquisa, projetos de extensão, projetos de educação à distância e continuada, etc. No ponto relativo à "Responsabilidade Social da Instituição" podem, de novo, ser encontradas referências que nos remetem para a ambientalização da instituição e para a construção da sustentabilidade:

No que tange a preservação do meio ambiente, o Programa de Mestrado Profissional em Planejamento Territorial e Desenvolvimento Socioambiental (MPPT) da Udesc está elaborando um projeto de sustentabilidade ambiental a ser desenvolvido pela Reitoria e todos os Centros de Ensino. Até o momento as ações em prol do meio ambiente, como coleta seletiva de lixo, reciclagem, conscientização dos servidores quanto à questão ambiental, são iniciativas isoladas dos Centros e não de uma política institucional (UDESC, 2016, p. 70).

A "Sustentabilidade financeira" simplesmente se refere à econômica. A partir da página 137 desenvolve-se o PPI que é um "importante instrumento teórico-metodológico que estabelece as políticas para a organização administrativa e pedagógica, norteando as ações voltadas para a consecução de sua missão e de seus objetivos" (UDESC, 2016, p. 137). Seu objetivo geral é constituir-se em um "documento teórico e conceitual que norteie a ação, a intervenção e a formulação das atividades universitárias, traduzindo sua filosofia e intencionalidade" (id. ibid.). A referência de que os fundamentos do PDI se respaldam na responsabilidade social, de imediato anuncia uma intenção, pelo menos teórica, de sustentabilidade. Entre os desafios complexos que o PPI identifica que a Udesc tem que superar contam-se os da "inovação", da "sustentabilidade", e da "inclusão social" (UDESC, 2016, p. 144). Logo em seguida, no que se refere à concepção de ensino e currículo o PPI refere-se à "inclusão de forma sustentável" (id. ibid.). Contudo um dos extratos que talvez expresse da melhor forma o compromisso com o ambiente e a sustentabilidade é o que se segue

O ensino em nível superior tem o objetivo de contribuir para a formação de um cidadão imbuído de valores éticos que, com competência técnica, possa atuar no seu contexto social de forma comprometida com a construção de uma sociedade mais justa, solidária e integrada ao ambiente. (UDESC, 2016, p. 145). 
Entre as diretrizes relativas à extensão refere-se: "Apoiar as ações acadêmicas da Universidade voltadas para a autonomia das comunidades e 0 desenvolvimento sustentável' (UDESC, 2016, p. 152). Entre os objetivos da responsabilidade social é citado "Promover o engajamento da UDESC no processo de inclusão social, de desenvolvimento sustentável e de preservação do patrimônio artístico e cultural' (UDESC, 2016, p. 165).

O Gráfico 1 apresenta os resultados da análise do PDI, no que se refere à percentagem de presença de cada um dos níveis considerados: gestão, ensino, extensão e pesquisa.

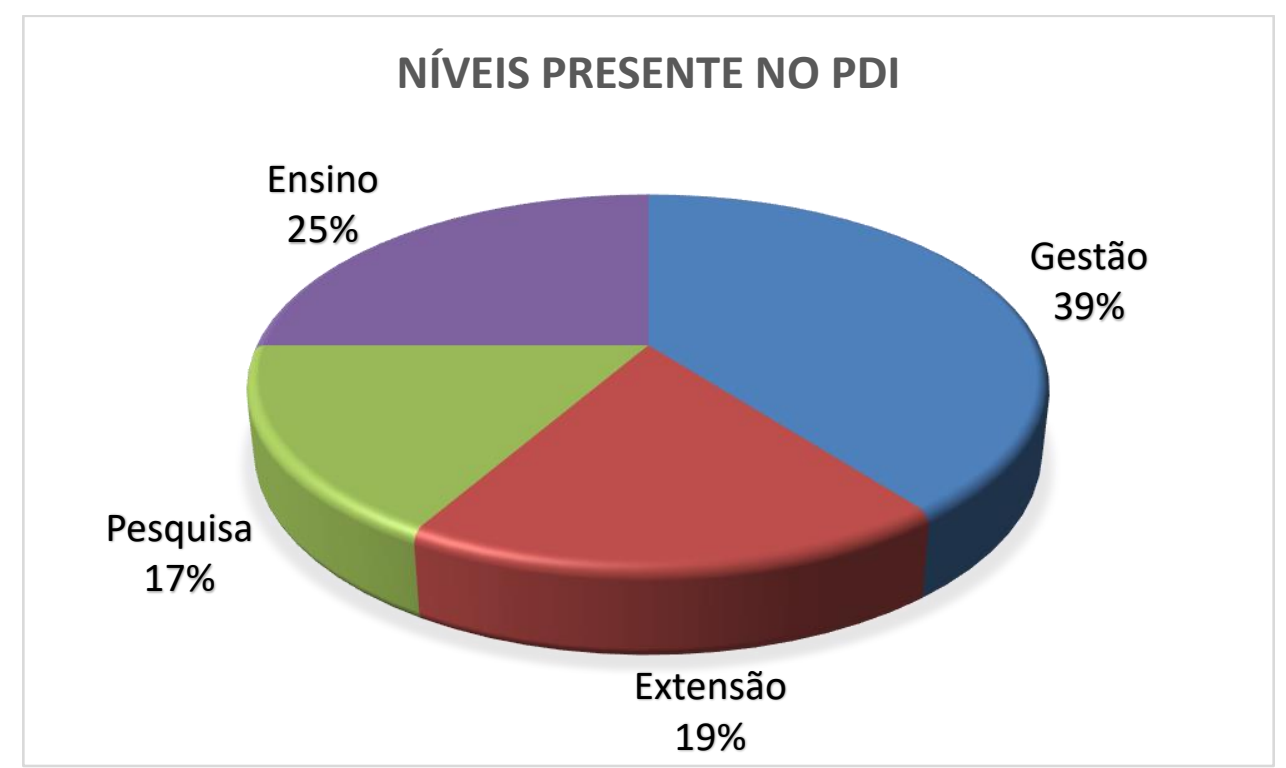

Gráfico 1: Percentagem de presença das palavras-chave das 11 dimensões por nível (gestão, ensino extensão e pesquisa).

Como se pode concluir da análise do gráfico, $39 \%$ das palavras-chave referentes às onze dimensões no PPI enquadram-se ao nível de gestão; $25 \%$ ao nível do ensino; 19\% ao nível da extensão; e 17\% ao nível da pesquisa, demonstrando que o PDI evidencia comprometimento com a temática ambientalização e sustentabilidade nos quatro níveis. Constata-se no gráfico 1 , na análise do PDI que o nível de gestão apresenta uma percentagem mais elevada do que nos demais níveis, principalmente, em relação à pesquisa conforme o fragmento "contribuir para o desenvolvimento local, regional e nacional, visando à melhoria da qualidade de vida da sociedade, com a busca da erradicação das desigualdades sociais e a utilização de tecnologias ecologicamente orientadas." Esta percentagem maior para a gestão (39\%) se justifica, pois, o referido documento enfatiza políticas voltadas para o desenvolvimento institucional, privilegiando mais o nível de ensino e da extensão do que o da pesquisa. Embora a percentagem de 39\% no nível de gestão apresente um indício de desenvolvimento sustentável e sustentabilidade, a Udesc ainda não possui políticas específicas para estas questões.

Revbea, São Paulo, V,13, № 1: 283-298, 2018. 


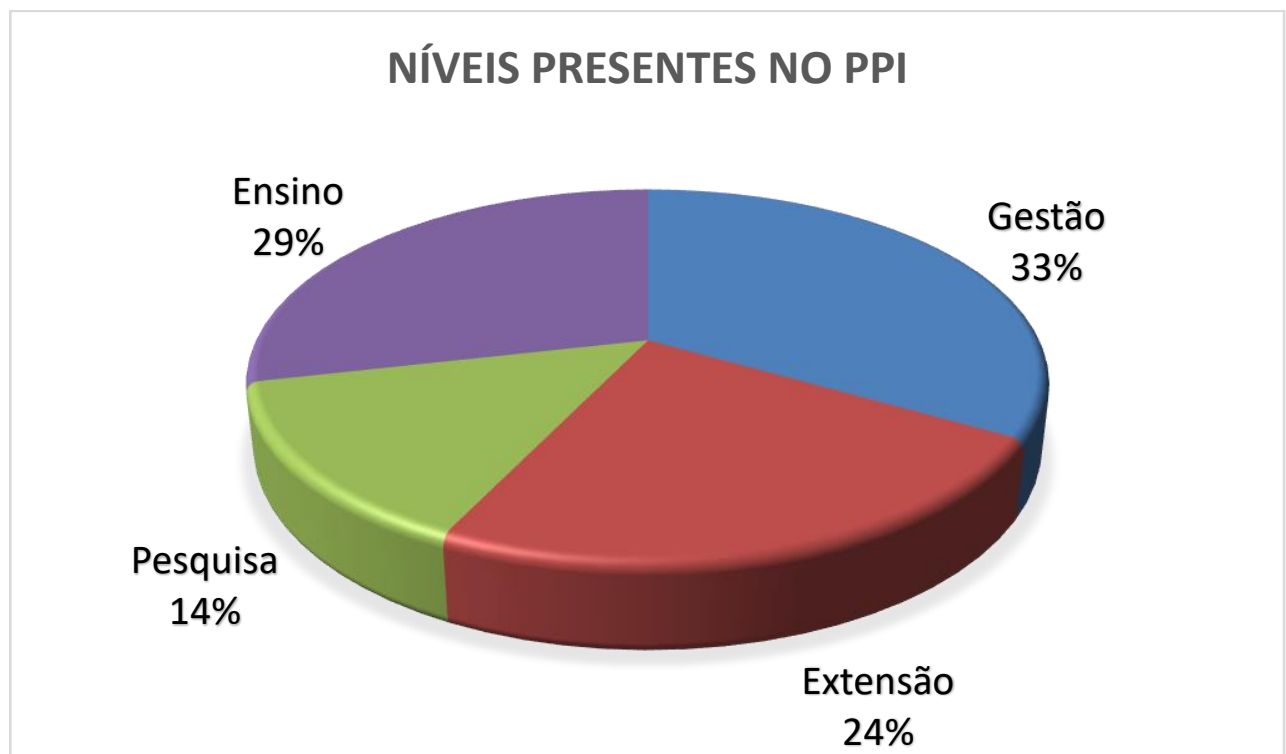

Gráfico 2: Percentagem das palavras-chave presentes nos níveis gestão, pesquisa, extensão e ensino no PPI.

De acordo com o Gráfico 2, 33\% das palavras-chave das 11 dimensões contempladas no PPI se referem ao nível da gestão; $29 \%$ ao nível do ensino, $24 \%$ ao nível da extensão e $14 \%$ se referem ao nível da pesquisa demonstrando que o PPI evidencia a responsabilidade com a temática desenvolvimento sustentável e sustentabilidade como por exemplo no trecho: "Os fundamentos do PPI da UDESC respaldam-se na responsabilidade social, nos compromissos culturais da Instituição, na autonomia universitária, na pluralidade de ideias e na concepção de educação, de ensino superior e de Universidade". E, no trecho "A qualidade da educação superior pressupõe 0 desenvolvimento, acompanhamento e avaliação constante das seguintes dimensões, conforme o Sistema Nacional de Avaliação da Educação Superior (SINAES): Missão e Plano de Desenvolvimento Institucional; Política para o Ensino, a Pesquisa, A pós- graduação e a Extensão; Responsabilidade Social; Comunicação com a sociedade ; Política de Pessoal; Organização e Gestão da Instituição; Infraestrutura Física; Planejamento e Avaliação; Políticas de Atendimento ao Estudante." Da mesma forma que foi apresentado no gráfico 1 (do PDI), observa-se neste Gráfico 2 que se repete uma percentagem menor para o nível da pesquisa em relação à gestão, ao ensino e à extensão. Embora a temática da sustentabilidade apareça no nível da pesquisa, ela ainda é muito modesta, demonstrando que a Udesc ainda precisa abordar o tema de forma mais equiparada em cada um dos níveis em seus documentos institucionais. 


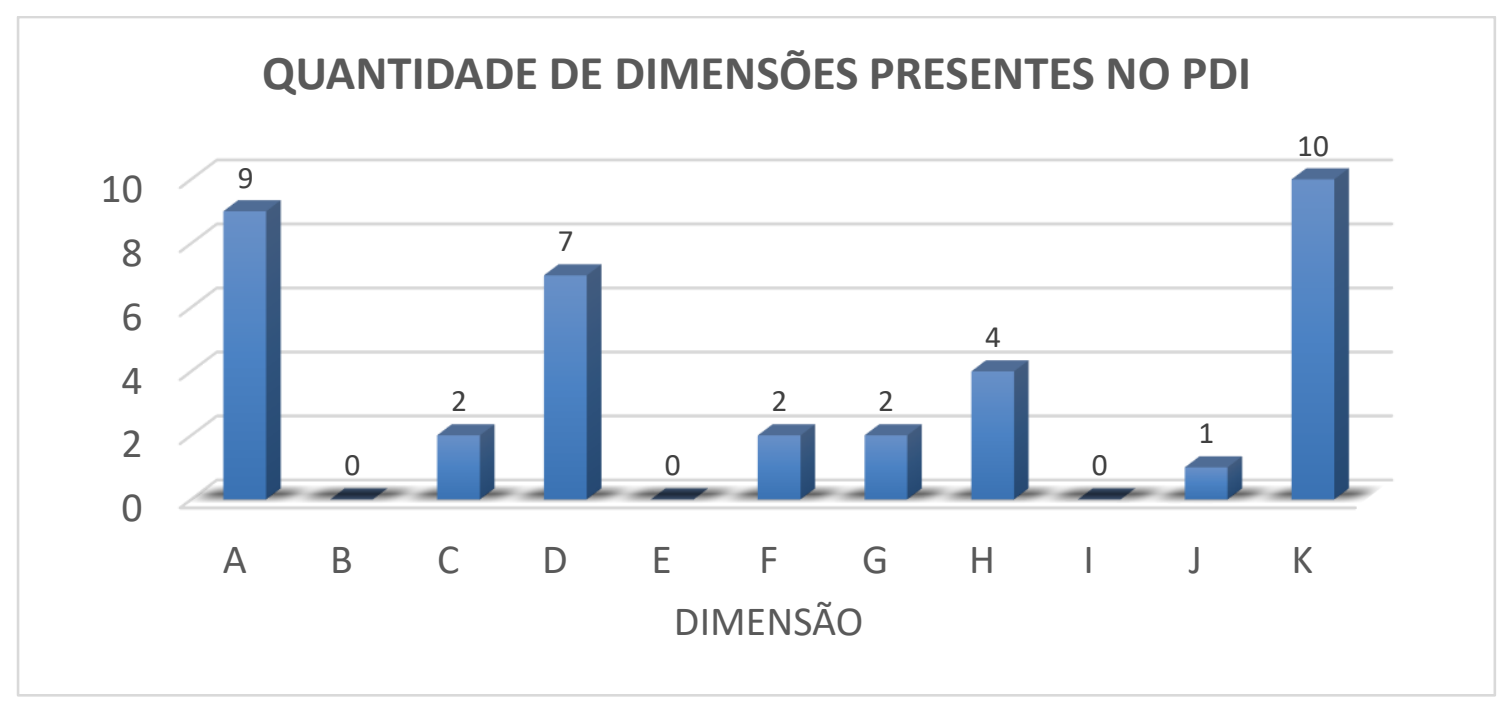

Gráfico 3: Quantidade de dimensões presentes no PDI.

Conforme Gráfico 3, no PDI destacam-se palavras-chave que contemplam predominantemente as dimensões $\mathbf{K}$ e $\mathbf{A}: \mathbf{K}$ - Adoção de valores como solidariedade, cooperação e responsabilidade (10) e a dimensão A Política de Ambientalização/ Sustentabilidade/Meio ambiente/Responsabilidade socioambiental (9).Em ordem decrescente a dimensão D (7) e H (4) apresentam mais palavras-chave do que as dimensões $\mathbf{C}(2), \mathbf{F}(2)$,e $\mathbf{G}(2)$. A dimensão $\mathbf{J}(1)$ foi comtemplada uma única vez e as dimensões $\mathbf{B}(0)$, E (0) e I (0) não tiveram palavras-chave contempladas no documento. Observa-se no gráfico 3 que no PDI houve predomínio já esperado, da dimensão $\mathbf{K}$ e $\mathbf{A}$, poiso referido documento institucional ressalta o compromisso da universidade com questões voltadas para o desenvolvimento de valores tão significativos socialmente e, embora não contemple efetivamente políticas de ambientalização, ganha destaque a incidência de trechos com enfoque no desenvolvimento sustentável e sustentabilidade.

Tabela 1: Quantidade de dimensões por níveis no PDI.

Dimensões

\begin{tabular}{l|c|c|c|c|c|c|c|c|c|c|c|}
\hline \multicolumn{1}{|c|}{ PDI } & A & B & C & D & E & F & G & H & I & J & K \\
\hline Gestão & 6 & 0 & 0 & 6 & 0 & 2 & 0 & 3 & 0 & 0 & 9 \\
Ensino & 3 & 0 & 0 & 3 & 0 & 1 & 2 & 2 & 0 & 0 & 7 \\
Extensão & 3 & 0 & 2 & 2 & 0 & 1 & 2 & 3 & 0 & 0 & 4 \\
Pesquisa & 1 & 0 & 0 & 2 & 0 & 1 & 1 & 1 & 0 & 1 & 1 \\
\hline
\end{tabular}

Em relação a distribuição das 11 dimensões e dos 4 níveis no PDI, conforme Tabela 1, obteve-se no nível da Gestão 26 trechos com palavraschave, sendo que 6 são da dimensão $A ; 6$ são da dimensão $D ; 2$ são da Revbea, São Paulo, V,13, № 1: 283-298, 2018. 
dimensão F; 3 são da dimensão H e 9 são da dimensão K. No nível de ensino foram codificados 18 trechos, sendo que 3 são da dimensão $A ; 3$ da dimensão D; 1 é da dimensão $F$; 2 da G; 2 são da dimensão $H$; 7 são da dimensão K. No nível extensão foram codificados 17 trechos, sendo que 3 são da dimensão $A ; 2$ são da dimensão $C$; 2 são da dimensão $D ; 1$ é da dimensão $F$; 2 são da dimensão G; 3 são da dimensão $H$; 4 são da dimensão $K$. No nível pesquisa foram codificados 8 trechos, sendo que 2 são da dimensão $D$ e apenas 1 nas seguintes dimensões: A, F, G, H, J, K. Salienta-se que não cabe somar os valores brutos, pois em alguns casos o mesmo trecho do documento foi inserido em mais de um nível e, às vezes, em mais de uma dimensão.

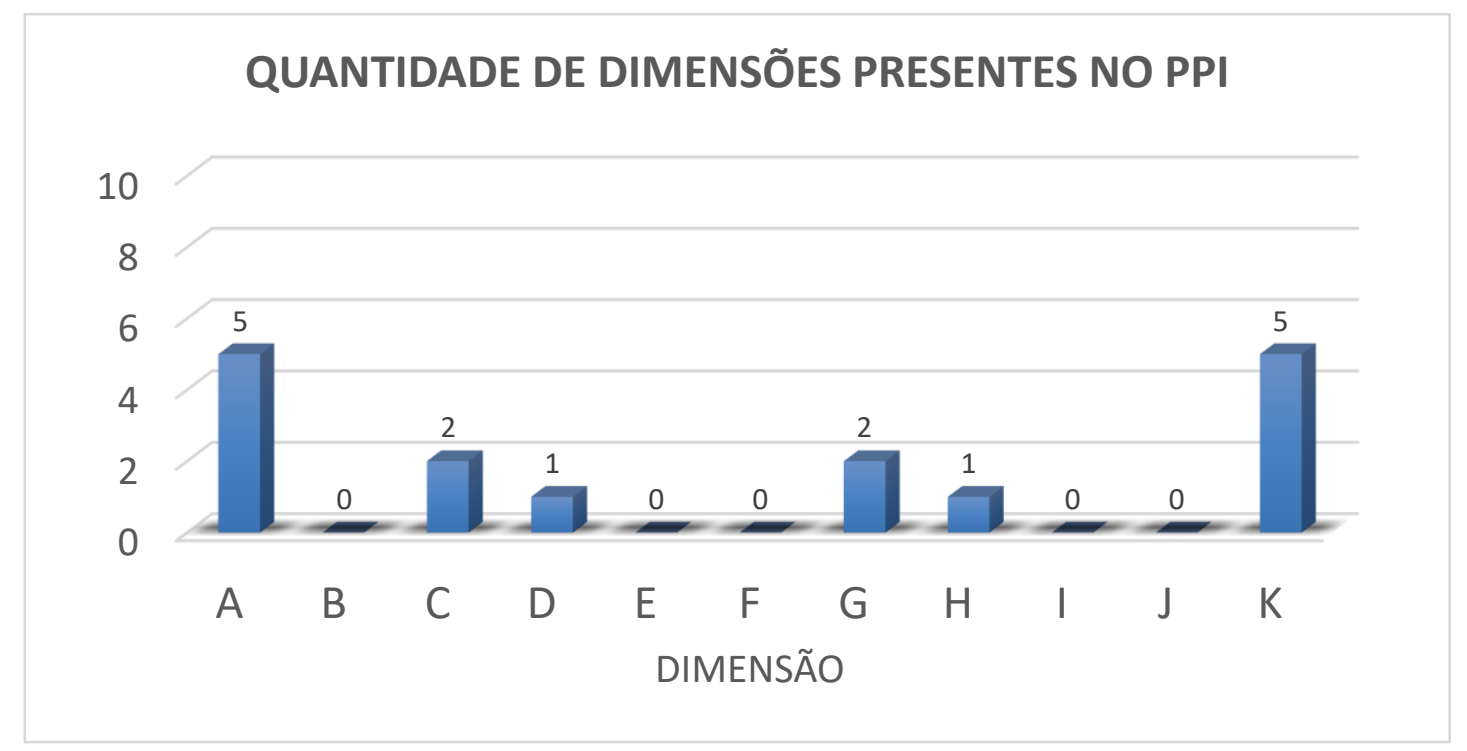

Gráfico 4: Quantidade de dimensões presentes no PPI.

Observa-se no Gráfico 4 também a predominância das dimensões AeK: A - Política de Ambientalização/Sustentabilidade/Meio ambiente/ Responsabilidade socioambiental (5); K - Adoção de valores como solidariedade, cooperação e responsabilidade (5). Em ordem decrescente a dimensão C e G (2) apresentam duas palavras-chave. As dimensões $\mathbf{D}$ e $\mathbf{H}$ (1) apresentam apenas uma. $\mathbf{E}$ as dimensões $\mathbf{B}, \mathbf{E}, \mathbf{F}, \mathbf{I}$ e $\mathbf{J}(0)$ não tiveram palavraschave contempladas no PPI. No PPI também houve predomínio da dimensão $\mathbf{A}$ e K, pois este documento é o Projeto Pedagógico Institucional e corresponde às ações e metas do PDI. Evidencia-se, assim uma coerência entre os dois documentos, embora no PPI a ocorrência seja quase a metade do PDI. Apesar de ser numericamente pouco expressivo, isto remete ao entendimento de que a Udesc caminha para o desenvolvimento de políticas voltadas para 0 desenvolvimento sustentável e sustentabilidade e para adoção de valores como solidariedade, cooperação e reponsabilidade social nos dois documentos Institucionais. Ainda no gráfico 4, no que se refere às dimensões: C sensibilização, participação democrática e comunicação (Educação Ambiental) e G - consideração dos sujeitos na construção dos saberes e fazeres; percebese que estas dimensões incidem duas vezes cada uma, tanto no PDI quanto no 
PPI indicando que há uma conformidade em ambos no que tange ao processo pedagógico. Para a dimensão D - compromisso para a transformação das relações ser humano-sociedade-natureza; observa-se que há no PDI um número bem mais expressivo (7) do que da mesma dimensão no PPI (1), porém ressaltase que o fato não necessariamente aponta para uma incoerência no PPI, pois observa-se que conforme as abordagens teóricas contempladas nos documentos as terminologias utilizadas podem diferir das palavras-chave codificadas pelo programa MAXQDA, e assim, não foram computadas. Para a dimensão H - consideração das relações com a comunidade e o entorno; notase que há no PDI um número maior (4) do que da mesma dimensão no PPI (1), evidenciando uma aparente desarticulação dos documentos, pois o projeto pedagógico não deveria estar centrado apenas no ensino, e sim articular o tripé ensino pesquisa e extensão. No que se refere as dimensões B-gerenciamento e/ou monitoramento de bens e serviços naturais (recursos), riscos e impactos ambientais; E- complexidade: diálogo em torno da ecologia de saberes, trabalho em redes; I- coerência e reconstrução entre teoria e prática; não houve incidência/ocorrência das mesmas no PDI e no PPI. Aparentemente este fato pode ser devido ao uso de diferentes terminologias usadas pela Udesc em relação às palavras-chave propostas nas dimensões. Embora não tenha ocorrido as dimensões B, E e I nos documentos, empiricamente pode - se dizer que a instituição trabalha as referidas dimensões. O mesmo fato percebe-se na dimensão F- contextualização local, global, local-global, global-local; em que no PDI aparece 2 vezes e não aparece no $\mathrm{PPI}$ e na dimensão J- construção de espaços permanentes de reflexão, formação e atualização; que aparece 1 vez no PDI e não há ocorrência no PPI.

Tabela 2: quantidade de dimensões por níveis no PPI

Dimensões

\begin{tabular}{l|c|c|c|c|c|c|c|c|c|c|c|}
\hline \multicolumn{1}{c|}{ PPI } & A & B & C & D & E & F & G & H & I & J & K \\
\hline Gestão & 4 & 0 & 1 & 1 & 0 & 0 & 1 & 1 & 0 & 0 & 4 \\
Ensino & 3 & 0 & 1 & 1 & 0 & 0 & 2 & 0 & 0 & 0 & 5 \\
Extensão & 3 & 0 & 1 & 0 & 0 & 0 & 2 & 0 & 0 & 0 & 3 \\
Pesquisa & 2 & 0 & 1 & 0 & 0 & 0 & 1 & 0 & 0 & 0 & 2 \\
\hline
\end{tabular}

De acordo com a Tabela 2, em relação a distribuição das 11 dimensões e dos 4 níveis, obteve-se no nível da Gestão 12 trechos codificados, sendo que 4 são da dimensão $A ; 1$ em cada uma das dimensões $C, D, G$ e H; 4 são da dimensão $K$. No nível do ensino foram codificados 12 trechos, sendo que 3 são da dimensão $A ; 1$ em cada uma das dimensões $C$ e $D ; 2$ na dimensão $G$ e 5 na dimensão K. No nível da extensão foram codificados 10 trechos, sendo que 3 são de cada uma das dimensões A e K; e 2 em cada uma das dimensões C e G. No nível da pesquisa, foram codificados 6 trechos, sendo que 2 são de cada uma das dimensões A e K; 1 em cada uma das dimensões C e G. Salienta-se que 
não cabe somar os valores brutos, pois em alguns casos o mesmo trecho do documento foi inserido em mais de um nível e, às vezes, em mais de uma dimensão.

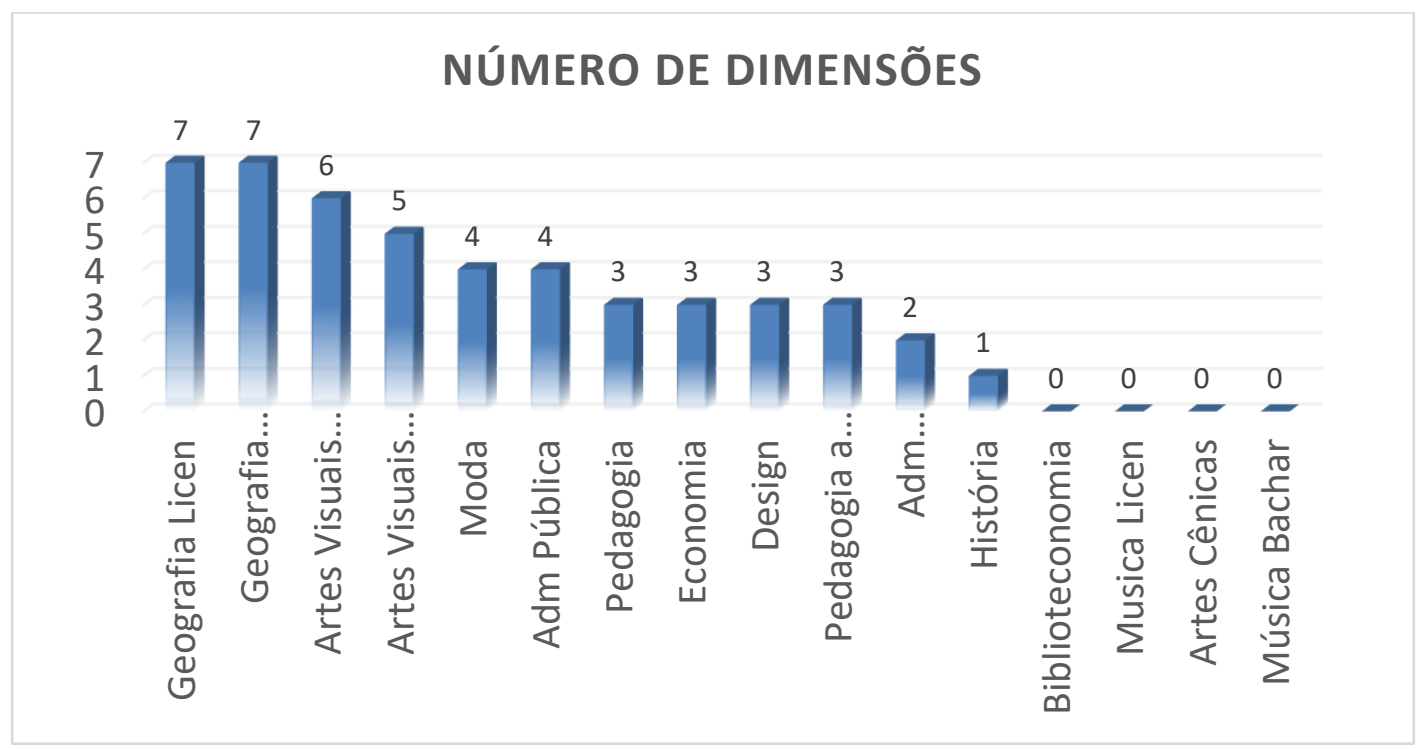

Gráfico 5: Número de dimensões presentes no total de 16 PPC da Udesc.

Conforme Gráfico 5, dos 16 cursos do campus I analisados, somente 10 apresentaram três ou mais dimensões. 7 dimensões em cada um dos cursos de Licenciatura e de Bacharelado em Geografia; 6 dimensões no curso de Bacharelado em Artes Visuais; 5 dimensões no curso de Licenciatura em Artes Visuais; 4 dimensões em cada um dos cursos de Moda e de Administração Pública; 3 dimensões em cada um dos cursos de Pedagogia, Economia, Design e Pedagogia a Distância; 2 dimensões no curso de Administração Empresarial; 1 dimensão no curso de História e zero dimensão para cada um dos cursos de Biblioteconomia, Licenciatura e de Bacharelado em Música e de Artes Cênicas. Embora o número de PPC analisados seja muito pequeno para representar toda a instituição, observa-se que nos 10 cursos analisados há incidência das dimensões o que permite dizer que há uma tendência, ainda que tênue, em inserir a universidade na dimensão da responsabilidade socioambiental. $O$ curso de Geografia (Licenciatura e Bacharelado) e o curso de Bacharelado em Artes Visuais são os que mais apresentam diferentes dimensões. Vale salientar que é urgente rever os PPC dos cursos que não apresentaram dimensões ou que apresentaram até duas delas. Essa revisão deve ser realizada envolvendo toda a comunidade acadêmica possibilitando o desenvolvimento de metas e de ações de responsabilidade ambiental e de desenvolvimento sustentável. 
Tabela 3: Quantidade de dimensões em cada curso do campus 1 da Udesc.

Dimensões

\begin{tabular}{|r|c|c|c|c|c|c|c|c|c|c|c|}
\hline PPC & $\mathbf{A}$ & $\mathbf{B}$ & $\mathbf{C}$ & $\mathbf{D}$ & $\mathbf{E}$ & $\mathbf{F}$ & $\mathbf{G}$ & $\mathbf{H}$ & $\mathbf{I}$ & $\mathbf{J}$ & $\mathbf{K}$ \\
\hline Geografia Licen & 2 & 1 & 1 & 4 & 1 & 0 & 0 & 1 & 0 & 1 & 0 \\
Geografia Bachar & 3 & 1 & 0 & 2 & 2 & 0 & 0 & 1 & 0 & 1 & 1 \\
Artes Visuais Bachar & 1 & 0 & 1 & 3 & 6 & 0 & 4 & 0 & 0 & 1 & 0 \\
Artes Visuais Licen & 1 & 0 & 0 & 5 & 6 & 0 & 4 & 0 & 0 & 0 & 1 \\
Moda & 5 & 0 & 1 & 0 & 0 & 1 & 0 & 0 & 0 & 0 & 2 \\
Pedagogia & 2 & 0 & 1 & 0 & 2 & 0 & 0 & 0 & 0 & 0 & 0 \\
Economia & 2 & 1 & 0 & 0 & 1 & 0 & 0 & 0 & 0 & 0 & 0 \\
Adm Pública & 2 & 1 & 0 & 0 & 0 & 1 & 0 & 0 & 0 & 0 & 2 \\
Adm Empresarial & 1 & 0 & 0 & 0 & 0 & 0 & 0 & 0 & 0 & 0 & 1 \\
Design & 1 & 0 & 1 & 2 & 0 & 0 & 0 & 0 & 0 & 0 & 0 \\
História & 0 & 0 & 0 & 1 & 0 & 0 & 0 & 0 & 0 & 0 & 0 \\
Pedagogia a Distância & 3 & 0 & 0 & 4 & 1 & 0 & 0 & 0 & 0 & 0 & 0 \\
Biblioteconomia & 0 & 0 & 0 & 0 & 0 & 0 & 0 & 0 & 0 & 0 & 0 \\
Música Licen & 0 & 0 & 0 & 0 & 0 & 0 & 0 & 0 & 0 & 0 & 0 \\
Artes Cênicas & 0 & 0 & 0 & 0 & 0 & 0 & 0 & 0 & 0 & 0 & 0 \\
Música Bachar & 0 & 0 & 0 & 0 & 0 & 0 & 0 & 0 & 0 & 0 & 0 \\
\hline
\end{tabular}

A Tabela 3 contempla a quantidade de dimensões codificadas nos projetos pedagógicos dos cursos analisados. No curso de Licenciatura em Geografia a dimensão $D$ teve maior destaque, conforme a ementa da disciplina de Educação Ambiental: "História da Educação Ambiental no Brasil e suas relações com as escolas dos movimentos operários e os estudos do meio. Análise das propostas de educação e meio ambiente nos documentos curriculares nacionais e catarinenses. Limites e possibilidades para uma prática escolar e social. Reflexões sobre o atual modelo de educação ambiental proposto às escolas e ao pensar ecologicamente correto. Sociedade de consumo. Sociedade de controle. Comunicação. Oficinas em Educação e Meio Ambiente". No curso de Geografia Bacharelado destaca-se o trecho codificado na dimensão A conforme a ementa da disciplina de Políticas Ambientais: "Políticas Públicas ambientais no mundo, no Brasil e em Santa Catarina. Os dilemas do Brasil frente a uma agenda de Políticas Públicas ambientais baseada na democracia, na equidade, na eficiência e na sustentabilidade. As Políticas Públicas ambientais alternativas. "No curso de Artes Visuais Bacharelado destaca-se o seguinte texto na dimensão $\mathrm{E}$ : "Entre as diretrizes principais que atravessam o Projeto Político Pedagógico do curso de Bacharelado em Artes Visuais, estão a ética, a estética e a ecologia. Compreende-se estes três referenciais como norteadores na formação dos profissionais que queremos formar, ou seja, indivíduos com capacidade auto reflexiva, capazes de lidar com Revbea, São Paulo, V,13, № 1: 283-298, 2018. 
os desafios que a civilização tecnoindustrial atual enfrenta. Concebendo o ser humano como um ser inserido num contexto maior, buscamos, instigar o amadurecimento de uma consciência planetária ampla ao mesmo tempo, que integrada e sintonizada com saberes e necessidades locais."

\section{Considerações finais}

Os resultados preliminares demonstram que a instituição apresenta registros de ambientalização e sustentabilidade por meio de políticas, ações e práticas internas e externas sustentáveis e de responsabilidade socioambiental reforçando o compromisso social da universidade em todos os níveis citados. Conclui-se que em todos os níveis se evidencia o comprometimento com a temática ambientalização e sustentabilidade, embora ainda numa perspectiva fragmentada e isolada nos documentos institucionais e curriculares. Diante dos indícios de ambientalização/sustentabilidade verificados nos documentos institucionais da Udesc considera-se que o estudo realizado, apesar de importante como base para pesquisas futuras, somente analisa as intenções de ambientalização e sustentabilidade presentes nos documentos institucionais. É necessário ainda dar continuidade e aprofundamento à investigação para identificar, caracterizar e avaliar que tipo de ações concretas, em termos de gestão, ensino, pesquisa e extensão estão sendo realizadas na Udesc englobando todos os seus campi. Ressalta-se que a ambientalização e a promoção da sustentabilidade são mudanças evolutivas do estado das coisas nas instituições e na sociedade e, neste contexto é importante o planejamento e a participação coletiva das universidades na construção de sociedades mais sustentáveis.

\section{Referências}

BARDIN, L. Análise de conteúdo. Lisboa: Edições 70, 2008.

BENAYAS, J.A. Proyecto RISU. Definición de indicadores para la evaluación de las políticas de sustentabilidad en Universidades Latinoamericanas. Resumen Ejecutivo. Madri, Universidad Autónoma de Madri, 2014.

CARNIATTO, I.; STEDING, A. Ambientalização e sustentabilidade nas universidades em debate. Revista Eletrônica Mestrado Educação Ambiental, v. 32, n.2, p. 299-318, jul./dez. 2015. Disponível em: $<$ https://www.seer.furg.br/remea/article/view/5545>.Acesso em: 6 set. 2016.

CUNHA, I.C. et al. Compromissos de sustentabilidade na Universidade do Estado de Santa Catarina- Udesc, Brasil: estudo de caso do projeto rede de indicadores de universidades sustentáveis - RISU. Revista Contrapontos Eletrônica, v.15, n.2, p.204-227, Itajaí, maio/ago. 2015. Disponível em: $<$ http://siaiap32.univali.br/seer/index.php/rc/issue/view/310/showToc $>$. Acesso em: 23 nov. 2016.

FRANCO, M.L.P.B. Análise de conteúdo. 3.ed. Brasília: Liber Livro Editora, 2008.

revista brasileira educação ambiental 
GUERRA, A. F. S.; FIGUEIREDO, M. L. Ambientalização curricular na Educação Superior: desafios e perspectivas. Educar em Revista, Curitiba, Brasil, Edição Especial n. 3/2014, p. 109-126. Editora UFPR.

GUERRA, A.F.S. et al. In: GUERRA, A.F.S. (Org.) Ambientalização e sustentabilidade nas universidades: [recurso eletrônico] subsídios, reflexões e aprendizagens. Dados eletrônicos. Itajaí: Ed. da UNIVALI, 2015.

HAGUETE, T.M.F. Metodologias qualitativas na sociologia. 9. ed. Petrópolis: Vozes, 2003.

JUNYENT M.; GELI, A. M.; ARBAT, E. (Org.). Ambientalización Curricular de los Estudios Superiores. 2 - Proceso de Caracterización de la Ambientalización Curricular de los Estudios Superiores. Girona: Editora UdG, 2003. v.40.

LEITE, E.B. et al. Puc Minas sustentável: plano de sustentabilidade ambiental. In: RUSCHEINSKY, A. et al. (Orgs.). Ambientalização nas instituições de educação superior no Brasil: caminhos trilhados, desafios e possibilidades. São Carlos: EESC/USP, 2014. p. 47-61.

LÜDKE, M.; ANDRÉ, M.E.D.A. Pesquisa em educação: abordagens qualitativas. São Paulo. E.P.U, 2003.

MAXQDA [computer software] VERBI Software. Consult. Sozialforschung. GmbH.v12.1.Berlin, Germany, 2016.

PIMENTEL, A. O método da análise documental: seu uso numa pesquisa historiográfica. Cad. Pesquisa, São Paulo, n. 114, p. 179-195, nov. 2001.

REDE DE INDICADORES DE UNIVERSIDADES SUSTENTÁVEIS- RISU. Disponível em: <http://ariusa.net/es/redes/sobre-risu>. Acesso em 13 fev. 2017.

ROCHA, G.S.D.C.; PEREIRA, M.G.; BARBOSA, A.T. Ambientalização curricular no curso de Ciências Biológicas numa universidade pública: primeiros resultados. Disponível em: $<$ http://www.nutes.ufri.br/abrapec/viiienpec/resumos/R1433-1.pdf>. Acesso em: 7 set. 2016.

RICHARDSON, R.J. Pesquisa social: métodos e técnicas. 3. ed. São Paulo. Atlas. 1999.

SORRENTINO, M.; BIASOLI, S. Ambientalização das instituições de educação superior: a educação ambiental contribuindo para a construção de sociedades sustentáveis. In: RUSCHEINSKY,A. et al. (Orgs.). Ambientalização nas instituições de educação superior no Brasil:caminhos trilhados, desafios e possibilidades. São Carlos: EESC/USP, 2014.p.39-46.

THIOLLENT, M. Metodologia da pesquisa-ação. São Paulo: Cortez, 2008.

UNIVERSIDADE DO ESTADO DE SANTA CATARINA. Plano de Desenvolvimento Institucional - PDI 2011-2016. Disponível em: $<$ http://www.esag.udesc.br/arquivos/id submenu/558/pdi $20112016 . p d f>$. Acesso em:14 set. 2016. 